\title{
Insulin stimulates $\beta$-alanine uptake in skeletal muscle cells in vitro
}

\author{
Lívia Santos $^{1}$ - L. S. Gonçalves ${ }^{2} \cdot$ Shirin Bagheri-Hanei ${ }^{3} \cdot$ Gabriella Berwig Möller $^{2} \cdot$ Craig Sale $^{1} \cdot$ Ruth M. James ${ }^{1}$. \\ Guilherme Giannini Artioli ${ }^{4}$ (D)
}

Received: 4 June 2021 / Accepted: 7 October 2021 / Published online: 21 October 2021

(c) The Author(s) 2021

\begin{abstract}
We evaluated whether insulin could stimulate $\beta$-alanine uptake by skeletal muscle cells in vitro. Mouse myoblasts $(\mathrm{C} 2 \mathrm{C} 12)$ ( $n=3$ wells per condition) were cultured with $\beta$-alanine $\left(350\right.$ or $\left.700 \mu \mathrm{mol} \cdot \mathrm{L}^{-1}\right)$, with insulin $\left(100 \mu \mathrm{U} \cdot \mathrm{mL}^{-1}\right)$ either added to the media or not. Insulin stimulated the $\beta$-alanine uptake at the lower $\left(350 \mu \mathrm{mol} \cdot \mathrm{L}^{-1}\right)$ but not higher $\left(700 \mu \mathrm{mol} \cdot \mathrm{L}^{-1}\right) \beta$-alanine concentration in culture medium, indicating that transporter saturation might blunt the stimulatory effects of insulin.
\end{abstract}

Keywords $\beta$-alanine $\cdot$ Insulin $\cdot$ Taurine transporter $\cdot$ Carnosine

\section{Introduction}

Carnosine ( $\beta$-alanyl-L-histidine) is found in the skeletal muscles of mammals $\left(\sim 10-40 \mathrm{mmol} \cdot \mathrm{kg}^{-1}\right.$ of dry muscle) (Harris et al. 2006), where it assists with $\mathrm{pH}$ regulation and antioxidant defences (Abe 2000; Carvalho et al. 2018). $\beta$-alanine is a constituent amino acid of carnosine and is found in low concentrations in skeletal muscle $(\sim 2 \mathrm{pmol} / \mu \mathrm{L})$ (Goncalves et al. 2020); its low availability is rate-limiting for carnosine synthesis (Harris et al. 2006). $\beta$-alanine availability can be increased via meat consumption or dietary supplementation. Although $\beta$-alanine supplementation increases skeletal muscle carnosine (Baguet et al. 2009), only 6\% of the total dose ingested contributes to this (Blancquaert et al. 2016). Because muscle carnosine is associated with

Handling editor: J. D. Wade.

Guilherme Giannini Artioli

G.Giannini.Artioli@mmu.ac.uk

1 Musculoskeletal Physiology Research Group, Sport, Health and Performance Enhancement Research Centre, Nottingham Trent University, Nottingham, UK

2 Applied Physiology and Nutrition Research GroupRheumatology DivisionFaculdade de Medicina FMUSPEscola de Educação Física E Esporte, Universidade de São Paulo, São Paulo, SP, Brazil

3 College of Engineering and Physical Science, Aston University, Birmingham B4 7ET, UK

4 Department of Life Sciences, Manchester Metropolitan University, John Dalton Building, Manchester M1 5GD, UK improved exercise capacity (Saunders et al. 2017) and has potential therapeutic benefits (Artioli et al. 2019), there is interest in developing strategies to optimise $\beta$-alanine transport into muscle cells to increase availability and enhance carnosine synthesis (Stegen et al. 2013).

The ingestion of $\beta$-alanine with meals increased intramuscular carnosine accretion compared with the ingestion of $\beta$-alanine between meals (Stegen et al. (2013); this was attributed to a putative increase in $\beta$-alanine transporter activity due to hyperinsulinemia. In contrast, our group showed that hyperinsulinemia did not, however, increase $\beta$-alanine uptake into human skeletal muscle when $\beta$-alanine and insulin concentrations were controlled (Goncalves et al. 2020). Two transporters (TauT, PAT1) are involved in $\beta$-alanine uptake and insulin could reduce their $K_{\mathrm{m}}$ or increase their $V_{\max }$, an effect secondary to the stimulatory effect of insulin on $\mathrm{Na}^{+} / \mathrm{K}^{+} /$ATPase pump activity and, ultimately, $\mathrm{Na}^{+}$influx (Clausen 2003; Sweeney and Klip 1998). Here, we sought to test the hypothesis that insulin can stimulate $\beta$-alanine uptake in skeletal muscle cells in vitro.

\section{Materials and methods}

Mouse myoblasts (C2C12, ATCC) were cultured under standard conditions in a humidified incubator at $37{ }^{\circ} \mathrm{C}$ and $5 \% \mathrm{CO}_{2}$ in high glucose $\left(4500 \mathrm{mg} \cdot \mathrm{L}^{-1}\right)$ basal medium Dulbecco's Modified Eagle's Medium (DMEM) supplemented with $10 \%$ heat inactivated fetal bovine serum and $100 \mathrm{U} \cdot \mathrm{mL}^{-1}$ penicillin/streptomycin until confluent. The 
medium was switched to differentiation medium (DM; high glucose DMEM supplemented with 2\% horse serum and 100 $\mathrm{U} \cdot \mathrm{mL}^{-1}$ penicillin/streptomycin) and cells were allowed to differentiate for 6 days. $\beta$-alanine was dissolved in DM to a concentration of 350 or $700 \mu \mathrm{mol} \cdot \mathrm{L}^{-1}$. Cell culture medium and supplements were purchased from Sigma-Aldrich. In one set of experiments, insulin was added to the DM to a concentration of $100 \mu \mathrm{U} \cdot \mathrm{mL}^{-1}$, while in another set, no insulin was added. To confirm whether the effect of insulin was mediated by TauT, mouse myoblasts were differentiated as described above and treated with $1 \mathrm{~mol} \cdot \mathrm{L}^{-1}$ hypotaurine (a competitive TauT inhibitor) for $24 \mathrm{~h}$ in DM to inhibit $\beta$-alanine uptake. The hypotaurine was discarded, the cells were washed with PBS and incubated with a 350 or $700 \mu \mathrm{mol} \cdot \mathrm{L}^{-1}$ of $\beta$-alanine with or without insulin $\left(100 \mu \mathrm{U} \cdot \mathrm{mL}^{-1}\right)$ in DM. Cells were incubated in these formulations for $24 \mathrm{~h}$. The concentration of $350 \mu \mathrm{mol} \cdot \mathrm{L}^{-1}$ of $\beta$-alanine was chosen to mimic typical plasma concentrations observed following the ingestion of commonly used $\beta$-alanine doses; the concentration of $700 \mu \mathrm{mol} \cdot \mathrm{L}^{-1}$ was chosen to saturate TauT $\left(K_{\mathrm{m}} \sim 40 \mu \mathrm{mol} \cdot \mathrm{L}^{-1}\right.$; Bakardjiev and Bauer 1994) and to mimic plasma concentrations elicited by high doses of $\beta$-alanine (Harris et al. 2006). The insulin concentration was chosen to mimic plasma insulin peaks following ingestion of a carbohydrate-rich meal (Stegen et al. 2013). Three independent experiments per condition, each in triplicate were carried out.

After completion, culture medium was collected, and cells washed with PBS and lysed with $2 \mathrm{~mL}$ of $0.5 \%$ Triton X-100 in $0.2 \mathrm{M} \mathrm{NaCl}$. One-hundred microliters of a $5 \%$ 5 -sulfosalicylic acid solution containing $500 \mu \mathrm{mol} \cdot \mathrm{L}^{-1}$ of norleucine (internal standard) was added and lysate homogenised. After incubating for $30 \mathrm{~min}$ at $4{ }^{\circ} \mathrm{C}$, the lysate was centrifuged at $10,000 \mathrm{rpm}$ for $5 \mathrm{~min}$ at $4{ }^{\circ} \mathrm{C}$, and the supernatant collected and filtered through a $0.22 \mu \mathrm{m}$ centrifugal filter tube. Intracellular $\beta$-alanine concentrations were determined via high-performance liquid chromatography ion exchange by injecting $40 \mu \mathrm{L}$ of the filtered supernatant through an automated amino acid analyser (Biochrom $30+$, Biochrom, Cambourne, UK). Serial dilution of amino acid standards (Merck, UK) with a constant internal standard concentration of $500 \mu \mathrm{mol} \cdot \mathrm{L}^{-1}$ allowed for quantitation. The column was maintained at a $50{ }^{\circ} \mathrm{C}$, and fluoraldehyde o-phthaldialdehyde was used for post-column derivatisation; the fluorescence detector was set at an excitation wavelength of $340 \mathrm{nM}$ and an emission wavelength of $450 \mathrm{nM}$. The software EZ Chrom Elite was used to determine peak area.

\section{Statistical analysis}

Data are presented as mean \pm SD with $95 \%$ confidence intervals $(95 \% \mathrm{CI})$. $\beta$-alanine concentrations in cell lysates were compared between conditions (supplemented with $\beta$-alanine with or without hypotaurine and insulin, and non-supplemented controls) with one-way ANOVA followed by the Tukey post-hoc where appropriate. Data were analysed in two data sets, those supplemented with $350 \mu \mathrm{mol} \cdot \mathrm{L}^{-1}$ or those with $700 \mu \mathrm{mol} \cdot \mathrm{L}^{-1}$ of $\beta$-alanine. Alpha level was set at 5\%. All analyses were carried out in the SAS statistical software (v.9.3; SAS Institute, Cary, $\mathrm{NC}$ ).

\section{Results}

\section{Cells supplemented with $350 \mu \mathrm{mol} \cdot \mathrm{L}^{-1}$ of $\beta$-alanine (Fig. 1)}

Incubation with $350 \mu \mathrm{mol} \cdot \mathrm{L}^{-1}$ of $\beta$-alanine increased $\beta$-alanine concentrations in cell lysates in all conditions $(F=339.13 ; p<0.0001)$. Insulin further increased intracellular $\beta$-alanine accrual in comparison with cells not treated with insulin $(t=-6.12 ; p=0.002 ; 95 \%$ CI -157.96 to - 43.93). Treatment with hypotaurine resulted in lower $\beta$-alanine concentrations in cell lysates in comparison with cells not treated with hypotaurine; this was shown either with $(t=21.01 ; p<0.0001 ; 95 \%$ CI 289.77-403.80) or without insulin $(t=18.37 ; p<0.0001 ; 95 \%$ CI 246.17-360.20). Despite the inhibitory effect of hypotaurine on $\beta$-alanine uptake, insulin increased $\beta$-alanine in hypotaurine-treated cells $(t=-3.48 ; p=0.04 ; 95 \% \mathrm{CI}-114.37$ to -0.34 , vs. hypotaurine-treated without insulin).

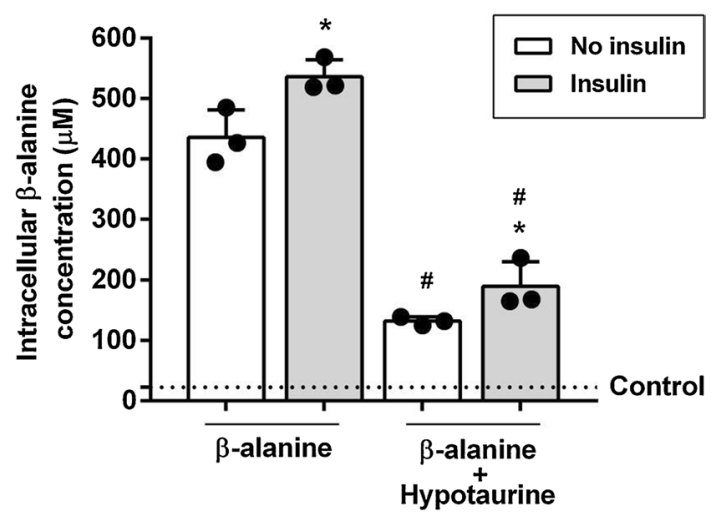

Fig. 1 Intracellular $\beta$-alanine concentration determined in lysate of myoblasts treated for $24 \mathrm{~h}$ with DM supplemented with $350 \mu \mathrm{mol} \cdot \mathrm{L}^{-1}$ $\beta$-alanine with or without insulin $\left(100 \mu \mathrm{U} \cdot \mathrm{mL}^{-1}\right)$ after treatment with hypotaurine or no treatment. Mean values measured in control cells are depicted by dotted lines. One-way ANOVA: all conditions are significantly different from control (all $p<0.0001$ ). Tukey post-hoc: no insulin $v s$. insulin: ${ }^{*} p=0.002$; no insulin $v s$. no insulin +hypotaurine ${ }^{\#} p<0.001$; insulin vs. insulin + hypotaurine ${ }^{\#} p<0.001$; no insulin +hypotaurine $v s$. insulin + hypotaurine: ${ }^{*} p=0.04 . n=3$ per condition 


\section{Cells supplemented with $700 \mu \mathrm{mol} \cdot \mathrm{L}^{-1}$ of $\beta$-alanine} (Fig. 2)

Incubation with $700 \mu \mathrm{mol} \cdot \mathrm{L}^{-1}$ of $\beta$-alanine led to an increase in $\beta$-alanine concentration measured in cell lysate in all conditions compared to control $(F=104.68$; all $p<0.0001)$. No significant differences were shown when comparing $\beta$-alanine between cells treated with and without insulin ( $t=-2.56 ; p=0.17 ; 95 \% \mathrm{CI}-181.77$ to 27.18$)$. Treatment with hypotaurine resulted in lower $\beta$-alanine concentrations in cell lysates compared with cells not treated with hypotaurine; this was shown with $(t=9.13 ; p=0.0001 ; 95 \%$ CI $171.75-380.71)$ and without insulin $(t=8.92 ; p=0.0001$; 95\% CI 165.19-374.14). Insulin did not increase $\beta$-alanine concentration in cells treated with hypotaurine $(\mathrm{t}=-2.34$; $p=0.23 ; 95 \% \mathrm{CI}-175.20$ to 33.75 ).

\section{Discussion}

$\beta$-alanine is primarily taken up into skeletal muscle cells in a saturable process undertaken by TauT, a $\mathrm{Na}^{+}$and $\mathrm{Cl}^{-}$dependent transmembrane transporter driven by $\mathrm{Na}^{+}$ flux, which is secondary to the action of the $\mathrm{Na}^{+} / \mathrm{K}^{+}$ATPase pump (Jessen 1994). Since the $\mathrm{Na}^{+} / \mathrm{K}^{+} /$ATPase pump and $\mathrm{Na}^{+}$influx are stimulated by insulin (Clausen 2003), hyperinsulinemia could increase TauT efficiency (Stegen et al. 2013), although direct experimental evidence for this is lacking. Herein, we showed that insulin can stimulate $\beta$-alanine transport into skeletal muscle cells, but only under lower $\left(350 \mu \mathrm{mol} \cdot \mathrm{L}^{-1}\right)$ and not higher $\left(700 \mu \mathrm{mol} \cdot \mathrm{L}^{-1}\right) \beta$-alanine concentrations in culture

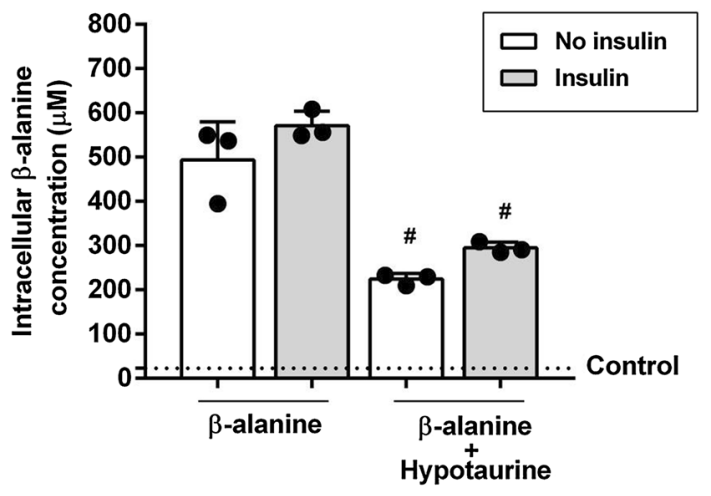

Fig. 2 Intracellular $\beta$-alanine concentration determined in lysates of myoblasts treated for $24 \mathrm{~h}$ with DM supplemented with $700 \mu \mathrm{mol} \cdot \mathrm{L}^{-1}$ $\beta$-alanine with or without insulin $\left(100 \mu \mathrm{U} \cdot \mathrm{mL}^{-1}\right)$ after treatment with hypotaurine or no treatment. Mean values measured in control samples are depicted by dotted lines. One-way ANOVA: all conditions are significantly different from control (all $p<0.0001$ ). Tukey posthoc: no insulin $v s$. no insulin + hypotaurine ${ }^{\#} p=0.0001$; insulin $v s$. insulin + hypotaurine ${ }^{\#} p=0.0001 . n=3$ per condition medium, indicating that transporter saturation might blunt the stimulatory effects of insulin. The reduced $\beta$-alanine uptake after incubation with hypotaurine confirmed that $\beta$-alanine transport to skeletal muscle cells is, at least in part, mediated by TauT, although we acknowledge that hypotaurine might impact other pathways that were not account for in this investigation.

Stegen et al. (2013) showed that chronic $\beta$-alanine supplementation in humans increased muscle carnosine concentration in the $m$. soleus, but not $m$. gastrocnemius, when $\beta$-alanine was ingested with meals (high insulin) when compared to between meals (low insulin). Conversely, an in vivo human study, using the hyperinsulinemic-euglycemic clamp, showed that hyperinsulinemia did not increase $\beta$-alanine uptake when substrate concentrations exceeded the $V_{\max }$ of TauT nor when it was below saturation of the $\beta$-alanine transporters (Goncalves et al. 2020). To further investigate the potential for insulin to influence $\beta$-alanine uptake by skeletal muscle, we used a cell culture model better suited to specifically test this hypothesis. Under saturating conditions of $\beta$-alanine $\left(700 \mu \mathrm{mol} \cdot \mathrm{L}^{-1}\right)$, no stimulatory effect of insulin on $\beta$-alanine uptake was shown, corroborating our earlier findings in humans (Goncalves et al. 2020) and supporting the notion that insulin does not increase the $V_{\max }$ of TauT. In contrast, when myoblasts media were supplemented with $350 \mu \mathrm{mol} \cdot \mathrm{L}^{-1}$ of $\beta$-alanine, insulin induced greater $\beta$-alanine uptake, both under normal conditions and when the TauT competitive inhibitor hypotaurine was administered. These findings indicate that, under lower $\beta$-alanine concentrations, insulin potentiates $\beta$-alanine transport into skeletal muscle, most likely by reducing the $K_{\mathrm{m}}$ of TauT, resulting in its increased activity and higher affinity for its substrates (Richter et al. 2019). We speculate that this is mediated by increased $\mathrm{Na}^{+}$gradients, secondary to increased $\mathrm{Na}^{+} / \mathrm{K}^{+} /$ATPase pump activity.

Although TauT is a major $\beta$-alanine transporter into muscle cells (Jessen 1994), a notion that is supported by the dramatic decrease in $\beta$-alanine accrual in the hypotaurinetreated cells, $\beta$-alanine can also be transported by PAT1, a $\mathrm{Na}^{+}$-independent, $\mathrm{H}^{+}$-dependent transporter (Frolund et al. 2010). Insulin could act upon PAT1 by stimulating the $\mathrm{Na}^{+} / \mathrm{H}^{+}$exchanger (Klisic et al. 2002) and, thus, one could argue that the higher $\beta$-alanine uptake with $350 \mu \mathrm{mol} \cdot \mathrm{L}^{-1}$ of $\beta$-alanine could also have occurred via a reduced $K_{m}$ of the PAT1 transporter. However, it is known that $\mathrm{Na}^{+}$increases PAT1 activity only in acidic conditions ( $\mathrm{pH} \sim 5.5-6.0)$ (Chen et al. 2003; Daniel et al. 1991), and since our experiments were performed within the $\mathrm{pH}$ range of resting skeletal muscle ( $\mathrm{pH} \sim 7.0$ ), an effect of insulin on the $\mathrm{Na}^{+} / \mathrm{H}^{+}$exchanger is unlikely. Assuming this to be correct, there would be little effect on PAT1 activity, meaning that the stimulatory effect of insulin would be due to the increased affinity of TauT for $\beta$-alanine. 
In conclusion, we demonstrate that insulin stimulates $\beta$-alanine uptake in skeletal muscle cells in vitro, possibly due to the increased affinity of TauT for $\beta$-alanine, but only when substrate concentration does not exceed its $V_{\max }$. More research is needed to determine whether this effect has relevant implications for whole-body physiology.

Author contributions L.S, L.S.G and GGA designed research; LS and R.J conducted research; L.S, LSG, G.M, C.K, RJ, CS and GGA analysed data. L.S, LSG, G.M, C.K, RJ, CS and GGA wrote the paper. All authors read and approved the final manuscript.

Funding L.S.G: Coordenação de Aperfeiçoamento de Pessoal de Nível Superior (CAPES); G.G.A: São Paulo Research Foundation-FAPESP (\#2014/11948-8; 2019/25032-9). This study was financed in part by the Coordenação de Aperfeiçoamento de Pessoal de Nível Superior-Brasil (CAPES-Finance Code 001).

\section{Declarations}

Conflict of interest All authors declare no competing interests in this study.

Research involving human participants and/or animals Not applicable.

Informed consent Not applicable.

Open Access This article is licensed under a Creative Commons Attribution 4.0 International License, which permits use, sharing, adaptation, distribution and reproduction in any medium or format, as long as you give appropriate credit to the original author(s) and the source, provide a link to the Creative Commons licence, and indicate if changes were made. The images or other third party material in this article are included in the article's Creative Commons licence, unless indicated otherwise in a credit line to the material. If material is not included in the article's Creative Commons licence and your intended use is not permitted by statutory regulation or exceeds the permitted use, you will need to obtain permission directly from the copyright holder. To view a copy of this licence, visit http://creativecommons.org/licenses/by/4.0/.

\section{References}

Abe H (2000) Role of histidine-related compounds as intracellular proton buffering constituents in vertebrate muscle Biochemistry. Biokhimiia 65:757-765

Artioli GG, Sale C, Jones RL (2019) Carnosine in health and disease. Eur J Sport Sci 19:30-39. https://doi.org/10.1080/17461391.2018. 1444096

Baguet A, Reyngoudt H, Pottier A, Everaert I, Callens S, Achten E, Derave W (2009) Carnosine loading and washout in human skeletal muscles. J Appl Physiol 106:837-842. https://doi.org/10.1152/ japplphysiol.91357.2008
Bakardjiev A, Bauer K (1994) Transport of beta-alanine and biosynthesis of carnosine by skeletal muscle cells in primary culture. Eur J Biochem 225:617-623. https://doi.org/10.1111/j.1432-1033. 1994.00617.x

Blancquaert L et al (2016) Carnosine and anserine homeostasis in skeletal muscle and heart is controlled by beta-alanine transamination. J Physiol 594:4849-4863. https://doi.org/10.1113/JP272050

Carvalho VH et al (2018) Exercise and beta-alanine supplementation on carnosine-acrolein adduct in skeletal muscle. Redox Bio 18:222-228. https://doi.org/10.1016/j.redox.2018.07.009

Chen $\mathrm{Z}$ et al (2003) Structure, function and immunolocalization of a proton-coupled amino acid transporter (hPAT1) in the human intestinal cell line Caco-2. J Physiol 546:349-361. https://doi.org/ 10.1113/jphysiol.2002.026500

Clausen T (2003) Na+-K+ pump regulation and skeletal muscle contractility. Physiol Rev 83:1269-1324. https://doi.org/10.1152/ physrev.00011.2003

Daniel H, Morse EL, Adibi SA (1991) The high and low affinity transport systems for dipeptides in kidney brush border membrane respond differently to alterations in $\mathrm{pH}$ gradient and membrane potential. J Biol Chem 266:19917-19924

Frolund S, Holm R, Brodin B, Nielsen CU (2010) The proton-coupled amino acid transporter, SLC36A1 (hPAT1), transports Gly-Gly, Gly-Sar and Other Gly-Gly Mimetics. Br J Pharmacol 161:589600. https://doi.org/10.1111/j.1476-5381.2010.00888.x

Goncalves LS et al (2020) Insulin does not stimulate beta-alanine transport into human skeletal muscle. Am J Physiol Cell Physiol 318:C777-C786. https://doi.org/10.1152/ajpcell.00550.2019

Harris RC et al (2006) The absorption of orally supplied beta-alanine and its effect on muscle carnosine synthesis in human vastus lateralis. Amino Acids 30:279-289. https://doi.org/10.1007/ s00726-006-0299-9

Jessen H (1994) Taurine and beta-alanine transport in an established human kidney cell line derived from the proximal tubule. Biochim Biophys Acta 1194:44-52

Klisic J, Hu MC, Nief V, Reyes L, Fuster D, Moe OW, Ambuhl PM (2002) Insulin activates $\mathrm{Na}(+) / \mathrm{H}(+)$ exchanger 3: biphasic response and glucocorticoid dependence. Am J Physiol Renal Physiol 283:F532-539. https://doi.org/10.1152/ajprenal.00365. 2001

Richter M, Moroniak SJ, Michel H (2019) Identification of competitive inhibitors of the human taurine transporter TauT in a human kidney cell line. Pharmacol Rep 71:121-129. https://doi.org/10. 1016/j.pharep.2018.10.005

Saunders B et al (2017) Twenty-four weeks of beta-alanine supplementation on carnosine content, related genes, and exercise. Med Sci Sports Exerc 49:896-906. https://doi.org/10.1249/MSS.00000 00000001173

Stegen S et al (2013) Meal and beta-alanine coingestion enhances muscle carnosine loading. Med Sci Sports Exerc 45:1478-1485. https://doi.org/10.1249/MSS.0b013e31828ab073

Sweeney G, Klip A (1998) Regulation of the Na+/K+-ATPase by insulin: why and how? Mol Cell Biochem 182:121-133

Publisher's Note Springer Nature remains neutral with regard to jurisdictional claims in published maps and institutional affiliations. 